\title{
ESCOLA E NOVA ESCOLA: FACES DE UM VELHO SONHO
}

\author{
Daniel Revah \\ Universidade Federal de São Paulo, Brasil.
}

\begin{abstract}
Resumo
Este artigo compara as edições inaugurais de dois periódicos educacionais do Grupo Abril: ESCOLA e Nova Escola. O primeiro é editado durante a ditadura militar, entre outubro de 1971 e abril de 1974, totalizando 27 números. O segundo é lançado logo após a retomada do regime democrático, em março de 1986, sendo editado até hoje, numa média de dez números anuais. Cerca de 15 anos separam o início das duas publicações, ambas dirigidas aos professores do $1^{\circ}$ Grau e muito semelhantes quanto à sua forma material. Outra característica comum e indissociável dessa forma material é o uso dos recursos do jornalismo e a sua venda em bancas de jornal. Apesar dessas semelhanças, a sua repercussão no campo educacional diferiu sobremaneira, pois a revista ESCOLA foi um fracasso do ponto de vista comercial e não parece ter alcançado relevância entre seus destinatários; ao contrário de Nova Escola, que teve forte penetração entre os professores. Ao comparar as edições inaugurais, este trabalho pretende analisar o modo como cada periódico busca situar-se diante de seus leitores, mas também em face de conjunturas políticas bem diversas (ditadura versus democracia). Com essa finalidade, serão focalizados e analisados os editoriais de apresentação e as capas da primeira edição, junto com as reportagens correspondentes e outros elementos dessas edições considerados importantes para desenvolver a questão proposta.

Palavras-chave: Grupo Abril, ESCOLA, Nova Escola, impresso educacional.
\end{abstract}

\section{ESCOLA AND NOVA ESCOLA: FACES OF AN OLD DREAM}

\section{Abstract}

This paper compares Inaugural editions for two Educational journals from April Group: ESCOLA and Nova Escola. The first was issued during the military dictatorship, between October 1971 and April 1974, with a total of 27 numbers in the circulation. Tthe second was released straight after the resumption of the democratic regime in March 1986, it has being published until today, with an average of ten issues a year. About 15 years separate the beginning of the two publications, both directed to primary school teachers and very similar in its material form. Another common characteristic and inseparable material is the use of the journalism resources and its sales at newsstands. Despite these similarities, their impact on the educational area differ greatly, because the ESCOLA magazine, in a commercial point of view was a failure and it does not seem to have 
achieved importance among of recipients, unlike Nova Escola, which had strong entry among teachers. By comparing the inaugural edition, this paper aims to examine how each journal seeks to situate itself in front of its readers, but also in the face of very different political circumstances (dictatorship $\mathrm{x}$ democracy). For this purpose, will be analyzed and focused the editorial presentation and the first edition covers along with the corresponding reportage and other elements of these issues considered important to develop the proposed question.

Key-words: Abril Group, ESCOLA, Nova Escola, printed educational.

\section{ESCOLA E NOVA ESCOLA: FACETAS DE UN VIEJO SUEÑO}

\section{Resumen}

Este artículo compara las ediciones inaugurales de dos revistas educativas del Grupo Abril: ESCOLA y Nova Escola. La primera fue editada durante la dictadura militar, entre octubre de 1971 y abril de 1974, llegando a un total de 27 números. La segunda fue lanzada poco después de la retomada del régimen democrático, en marzo de 1986, con ediciones periódicas hasta hoy y una media de diez números anuales. Cerca de 15 años separan el inicio de las dos publicaciones, ambas dirigidas a los profesores de la escuela primaria y muy semejantes en cuanto a su forma material. Otra característica común y indisociable de esa forma material es el uso de los recursos del periodismo y su venta en kioscos. A pesar de esas semejanzas, su repercusión en el campo educativo fue muy diferente, pues la revista ESCOLA fracasó del punto de vista comercial y aparentemente no llegó a ser relevante entre sus destinatarios; al contrario de Nova Escola, que tuvo fuerte aceptación entre los profesores. Por medio de la comparación de las ediciones inaugurales, este trabajo pretende analizar la manera como cada revista busca situarse ante sus lectores, pero también delante de coyunturas políticas bien diferentes (dictadura $\mathrm{x}$ democracia). Con esa finalidad, serán focalizados y analizados los editoriales de presentación y las capas de la primera edición, junto con los reportajes correspondientes y otros elementos de esas ediciones considerados importantes para desarrollar la cuestión propuesta.

Palabras clave: Grupo Abril, ESCOLA, Nova Escola, impreso educacional.

\section{ESCOLA ET NOVA ESCOLA: VISAGES D'UN VIEUX REVE}

\section{Résumé}

Cet article fait la comparaison entre les éditions inauguraux de deux périodiques éducationaux de la maison d'édition Grupo Abril: ESCOLA et Nova Escola. Le premier a été édité pendant la dictature militaire, entre octobre 1971 et avril 1974, totalisant 27 numéros. Le second est publié immédiatement après la reprise du régime démocratique, mars 1986, étant édité jusqu'aujourd'hui, en moyenne 10 números par an. Environ 15 ans separent le début des publications, les deux sont dirigées aux professeurs du $1^{\text {er }}$ dégré et sont très pareille en ce qui concerne sa forme matérielle. L'autre caractéristique normale et inséparable de cette forme matérielle est l'utilisation des recours du journalisme et à sa vente en kiosque à journaux. Malgré ses similarités, sa répercussion dans le domaine éducatif diffèrent considérablement, puisque la revue ESCOLA a été un échec du point de vu commercial et ne semble pas avoir atteint importance parmis ses destinataires ; au contraire de Nova Escola, qu'a eu une forte pénétration parmis les professeurs. En comparant les éditions inauguraux, ce travail prétend analyser la façon de comment chaque périodique cherche se situer face à leurs lecteurs, mais aussi face à une conjecture politique bien différente (dictature $x$ démocracie). Avec ce but, les éditoriaux de présentation et les couvertures de la première édition seront focalisés et analysés, et d'autres éléments de ces éditions considérées importantes pour développer la question proposée.

Mots-clé: Grupo Abril, ESCOLA, Nova Escola, publication pédagogique. 
A Editora Abril, inaugurada oficialmente por Victor Civita em 1950, em algumas décadas tornou-se a maior editora de revistas comerciais do Brasil. ${ }^{1}$ Com revistas como Claudia, Quatro Rodas e Veja, já nos anos de 1960 destaca-se pelo sucesso de suas publicações e pelo atendimento a públicos diversos, com interesses específicos, seguindo a tendência cada vez mais acentuada de segmentação do mercado de revistas.

No campo educacional, a Editora Abril faz a sua primeira incursão com um periódico educacional no ano de 1971, em outubro, no mês em que se comemora o dia do professor. Com o número zero, a edição inaugural da revista ESCOLA é apresentada pelo próprio Victor Civita, no editorial de mais um empreendimento para um público específico, desta vez os professores do $1^{\circ} \mathrm{Grau}$, o nível de ensino criado pelo regime militar nesse mesmo ano, por meio da lei n. 5.692/71.

O primeiro periódico educacional da Editora Abril tem uma vida curta, pois deixa de ser publicado em abril de 1974, quando totaliza 27 números. Nova tentativa é feita em meados da década seguinte, com um título que remete para a publicação anterior: Nova Escola. Lançada logo após o fim da ditadura militar, em março de 1986, a revista é apresentada como uma publicação da Fundação Victor Civita, que foi criada em 1985 e pertencia ao grupo empresarial iniciado com a Editora Abril, à época com uma ampla e diversificada atuação no mercado. ${ }^{2}$ A nova publicação do Grupo Abril é bem sucedida e continua a ser editada até os dias de hoje, numa média de dez números anuais.

Cerca de 15 anos separam o início das duas publicações, ambas dirigidas aos professores do $1^{\circ}$ Grau e muito semelhantes quanto à sua forma material. Outra característica comum e indissociável dessa forma material é o uso dos recursos do jornalismo e a sua venda em bancas de jornal. Apesar dessas semelhanças, a sua repercussão no campo educacional diferiu sobremaneira, pois a revista ESCOLA foi um fracasso do ponto de vista comercial e não parece ter alcançado relevância entre seus destinatários; ao contrário de Nova Escola, que teve forte penetração entre os professores.

O objetivo deste trabalho é comparar as edições iniciais desses dois periódicos, atentando para o modo como buscam situar-se nesse momento inaugural diante de seus leitores, mas também em face de conjunturas políticas bem diversas. Com essa finalidade, serão focalizados e analisados os editoriais de apresentação e as capas da primeira edição, junto com as reportagens correspondentes e outros elementos dessas edições considerados importantes para desenvolver a questão proposta.

As significações que definem o lugar em que esses periódicos procuram situar-se no momento de seu lançamento, e que em última instância concernem ao lugar do próprio Grupo Abril, são analisadas neste trabalho tendo em vista as características materiais do suporte, de maneira a seguir nesse ponto o que a história cultural postula com Chartier sobre a necessidade de considerar os sentidos das formas, pois, como ele diz, "não há

\footnotetext{
${ }^{1}$ Ao findar o século 20, o Grupo Abril era responsável por "64\% do mercado brasileiro de revistas" (Pereira, 2010, p. 305).

2 A ampliação e diversificação do Grupo Abril continuou nas décadas seguintes. Além da Editora Abril, em 2004 compreendia a TVA, a MTV e as editoras Ática e Scipione, constituindo um dos maiores grupos de comunicação da América Latina (Pereira, 2010, p. 305; Charnizon, 2008, p. 18 e 37 ).
} 
compreensão de um escrito, qualquer que ele seja, que não dependa das formas através das quais ele chega ao seu leitor" (1990, p. 127).

Nessas significações, uma dimensão importante é a representação do leitor visado por essas publicações e que elas próprias criam no momento em que procuram definir seu lugar no mercado, em conformidade também com determinada conjuntura política e cultural. Embora nos dois casos o leitor visado e a forma material sejam, à primeira vista, bem semelhantes, dando lugar a pensar que a segunda publicação é tão-somente uma retomada da primeira (Pedroso, 1999; Silveira, 2006), nas entrelinhas dessas semelhanças e em elementos menos implícitos podemos encontrar as diferenças que as conjunturas políticas evidenciam e que uma análise comparativa pode fazer emergir como faces distintas e até opostas do que, à maneira de um leitmotiv, move um grupo empresarial como o Grupo Abril. Essas faces distintas, que aqui serão expostas por meio da análise das opções editoriais de cada periódico no momento inaugural, fazem parte também de um velho sonho de seu fundador, um sonho que em última instância define o próprio Grupo Abril.

\section{A serviço de um velho sonho}

Lançada em outubro de 1971, a revista ESCOLA é apresentada no editorial inaugural por Victor Civita, que qualifica o primeiro exemplar de experimental, um adjetivo que pode ser estendido à própria revista. ${ }^{3}$ Encerrada a sua publicação cerca de três anos mais tarde, justifica-se a sua interrupção no editorial do último número, em abril de 1974, aludindo-se à "sensação frustrante do mestre que não conseguiu dar uma determinada aula por lhe faltarem os materiais necessários" (Civita et al, 1974, p. 3). Os leitores são informados que houve um "violento aumento de custo do papel" e a "necessidade de redefinirmos os objetivos e a política editorial da revista" (Civita et al, 1974, p. 3). ${ }^{4}$ Em meados da década seguinte, em março de 1986, ocorre o lançamento da revista Nova Escola, com um projeto editorial à primeira vista semelhante e um nome que alude implicitamente à fracassada publicação anterior, que sequer é mencionada no editorial que abre o primeiro número, igualmente assinado pelo fundador do Grupo Abril. Nesse editorial afirma-se que a nova publicação é "resultado de um velho sonho", o qual sugere certo vínculo com a frustrada iniciativa anterior, como se o sonho fosse comum a ambas (Civita, 1986, p. 5).

\footnotetext{
${ }^{3}$ A respeito do caráter experimental da própria revista, em razão do que ela representava como projeto gráfico e editorial diferenciado em face do que predominava entre os periódicos educacionais da época, veja-se Revah e Toledo (2010).

${ }^{4}$ Num estudo de caso sobre a revista ESCOLA publicado em 1979 afirma-se que essa publicação não recebia subsídios de órgãos estatais, mantendo-se com a venda de exemplares avulsos em bancas de jornal, assinaturas e anúncios (Rosenberg et al., 1979, p. 59-60). Fala-se também que as vendas de assinaturas esbarravam em obstáculos de dois tipos: a desorganização dos serviços do Correio brasileiro e as deficiências do próprio departamento da editora responsável pelas assinaturas (ibid., p. 59-60). Tentou-se, mas sem sucesso, a venda de assinaturas em bloco e com desconto a órgãos de governo, que as revenderia aos professores (p. 61). Sobre as hipóteses a respeito das razões que levaram ao encerramento dessa publicação, veja-se também Revah e Toledo (2010 e 2011) e Vieira (1995, p. 22), que apresenta "um documento de circulação interna" da revista Nova Escola que se refere à publicação anterior.
} 


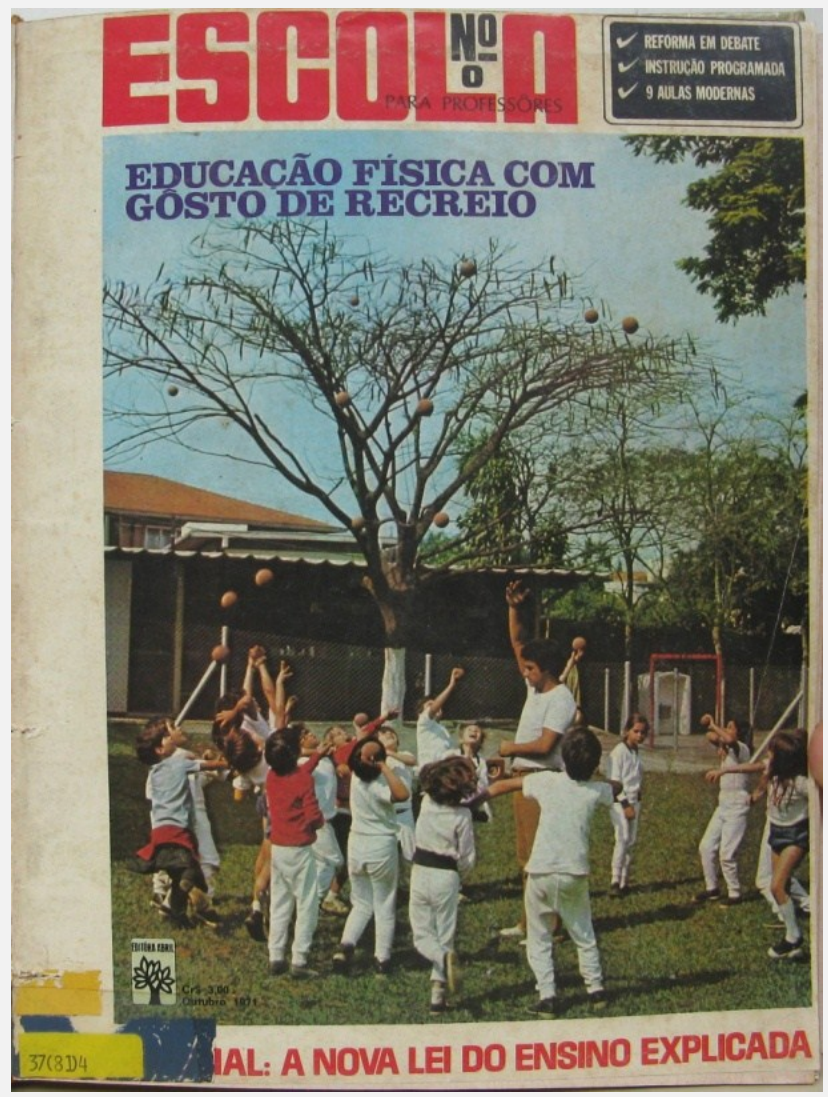

Desse sonho faz parte a mesma intenção de se diferenciar dos periódicos educacionais que tradicionalmente tiveram como destinatário o professor e cujos projetos editoriais são alvo de crítica no editorial da primeira revista, uma crítica que não deixa de estar implicada no editorial da segunda. Na primeira publicação, Civita afirma que esse "setor", o das revistas pedagógicas, "se tem caracterizado pelo mais insistente arcaísmo" e deixa em evidência o diferencial da nova publicação da Editora Abril com estas palavras: "acreditamos que pela primeira vez, no Brasil, seja feita uma revista pedagógica com os recursos do jornalismo ou, em outras palavras, com a forma jornalística a serviço do conteúdo pedagógico" (Civita, 1971, p. 3). O fundador da Editora Abril alega que esse é o meio de torná-la "atraente" e de aproveitar "os recursos da comunicação", nesse caso tendo como alvo o "Caro Professor", a quem se dirige na chamada "Apresentação" (Civita, 1986, p. 5). Esse leitor é constantemente lembrado no nome da própria revista, complementado em todas as capas pela expressão para professores.

A publicação que a sucede em meados da década de 1980 também é dirigida ao professor de $1^{\circ} \mathrm{Grau}$, inclusive nas capas, por meio de uma expressão semelhante à anterior: para professores do $1^{\circ} \mathrm{Grau}$. Mas desta vez, além de indicar o nível do ensino na capa, o editor mostra-se atento ao gênero predominante nesse nível. A intitulada "carta do editor", assinada igualmente por Victor Civita, começa com "Prezada Professora", embora no texto o destinatário seja ampliado: "para o estudante de Pedagogia, de Letras, do Normal e para todos aqueles que, de uma forma ou de outra, estão envolvidos com o processo de Educação no país" (Civita, 1986, p. 5).

A pretensão de ser atraente agora se encontra implicada na ideia da revista ser um "elemento de leitura agradável e instrutiva" (idid., p. 5). Outros projetos editoriais não são expressamente criticados, mas essa posição não deixa de transparecer quando Civita afirma que a revista "não é nem deseja ser uma publicação pedagógica", ao contrário inclusive do que dizia no editorial inaugural da revista anterior (ibid., p. 5). Além disso, salienta que a revista Nova Escola é o resultado de "um longo trabalho de uma equipe de experimentados jornalistas e profissionais da Educação" (ibid., p. 5). De modo que o fundador da Editora Abril continua ressaltando o viés jornalístico, embora também faça referência aos "profissionais da Educação" que fazem parte da "equipe" que produz a revista, não mencionados na "Apresentação" da publicação da década de 1970 (ibid., p. 5). Nesta nova publicação, portanto, não mais se fala em revista pedagógica, apesar da referência aos profissionais da educação que nela trabalham, como se estes tivessem sido deslocados do lugar que lhes seria próprio, o pedagógico, para serem situados no 
âmbito do jornalismo, implícito na recusa do adjetivo pedagógico e na menção feita aos "experimentados jornalistas" (ibid., p. 5).

Nesses editoriais inaugurais, a forma jornalística também sobressai quando se explicita o modo como as revistas serão disponibilizadas a seus professores-leitores: nas bancas de jornal. Na revista ESCOLA, essa forma de circulação e aquisição do periódico é ressaltada no trecho em que a editora é apresentada como "pioneira no campo editorial" e "a serviço do homem brasileiro", "há vinte anos, participando do desenvolvimento do país e do esforço nacional no sentido da difusão do conhecimento" (Civita, 1971, p. 3).

A Editora Abril, lembra Civita, "coloca nas bancas de jornal de todo o país, diariamente, milhões de exemplares de publicações culturais que, de outra forma, ficariam circunscritas a bibliotecas e livros pouco acessíveis à maioria da população" (idid., p. 3). Atingir a maioria, ser uma editora de massas, no período em que a indústria cultural está em franco desenvolvimento, é um dos registros em que pode ser retrospectivamente situado o velho sonho mencionado na revista que surge posteriormente. Nesse sonho, no qual repartir cultura e vender cada vez mais andam entrelaçados, as bancas de jornal constituem uma estratégia central, mas ela já não é destacada no editorial da década de $1980 .^{5}$

Na revista Nova Escola é feita apenas uma breve referência no final da "carta do editor", após a assinatura de Civita, por meio de um P.S., no qual se aponta em letras miúdas que a revista estará mensalmente "em todas as bancas de jornais e revistas do país" (Civita, 1986, p. 5). Ademais, não é mencionada a Editora Abril. Agora o que é destacado é a Fundação Victor Civita, com o nome escrito no editorial em caixa alta, à semelhança do nome da revista nesse mesmo texto. Na capa da nova revista observa-se também que o logotipo da Editoria Abril, presente nas capas de ESCOLA, foi substituído pelo logotipo da Fundação.

Ao se dirigirem ao professor ou professora, ambos editoriais referem-se aos objetivos da nova publicação. A revista ESCOLA é proposta como "instrumento de diálogo e cooperação com o professor de $1^{\circ} \mathrm{Grau}$, em benefício do ensino e da educação no Brasil" (Civita, 1971, p. 3). Justifica-se ademais a opção pelo $1^{\circ}$ Grau porque "nesse setor [...] se localizam os maiores problemas do ensino", porque nele "uma publicação pedagógica pode ser útil ao maior número" e, finalmente, porque na implantação e aperfeiçoamento desse nível de ensino reside "a esperança do êxito do gigantesco esforço desenvolvido pelo governo federal e pelos Estados no sentido de dar ao país o ensino adequado às suas necessidades presentes e futuras" (idid., p. 3).

O "gigantesco esforço" mencionado por Civita concerne à Reforma de Ensino do regime militar, instituída pela lei 5.692/71, que cria o $1^{\circ}$ e $2^{\circ}$ Graus (idid., p. 3). ${ }^{6} \mathrm{~A}$ seguir, o editorial ressalta a simultaneidade aí implicada, transformando-a assim, ela própria, em um acontecimento, em um fato digno de nota: "A revista ESCOLA chega com a reforma do ensino e desde já, entusiasticamente, se coloca a serviço dela. Como diz um dos

\footnotetext{
${ }^{5}$ A respeito desse entrelaçamento, é sugestiva esta afirmação de Civita sobre o vendedor ideal de livros: ele "tem consciência da importância do produto que oferece e vende, vende, vende! E que faz a venda, convicto que está não só vendendo, mas divulgando conhecimentos, repartindo cultura" (Civita, 1974 apud Pereira, 2010, p. 310). Já desde os anos de 1960 a principal estratégia da Editora Abril para a venda de seus produtos foi a utilização de bancas de jornal (Pereira, 2010, p. 306).

${ }^{6} \mathrm{~A}$ reforma do ensino criou o $1^{\circ}$ e $2^{\circ}$ graus e reorganizou os níveis do ensino, ao reunir no primeiro nível a escola primária e o ginásio, que antes da reforma fazia parte do secundário.
} 
nossos colaboradores [...] trata-se de algo mais que uma reforma: é uma nova concepção da escola e do ensino" (idid., p. 3). O editorial termina afirmando que o n. 1 da revista ESCOLA será lançado em março de 1972, "no momento em que começará uma das mais audaciosas fases de toda a história do ensino no Brasil" (idid., p. 3). Vê-se então que o editorial inaugural procura envolver o professor na mudança em curso de forma laudatória, sem economizar elogios às políticas educacionais da ditadura.

Com o retorno da democracia, em meados da década de 1980, Civita apresenta a revista Nova Escola destacando objetivos em parte semelhantes ou próximos aos da publicação anterior, como estes: "fornecer à professora informações necessárias a um melhor desempenho do seu trabalho" e "proporcionar uma troca de experiências e conhecimentos entre todas as professoras brasileiras de $1^{\circ}$ Grau" (Civita, 1986, p. 5). À semelhança de ESCOLA, alude também a uma mudança em curso nesse momento e desta vez explicita que a revista busca integrar a professora "ao processo de mudança que ora se verifica no país", deixando implícito o sentido ou natureza dessa mudança (idid., p. 5). Na época, celebrava-se a volta da democracia, com a chamada Nova República, após 20 anos de ditadura militar.

A nova revista do Grupo Abril nasce sintonizada com essa mudança, com a qual implicitamente se vincula por meio do significante nova presente em seu nome, estabelecendo também desse mesmo modo certa distância em relação ao próprio passado, no qual confundia-se com o regime na sua enfática defesa das suas políticas educacionais. A única indicação explícita a respeito do sentido dessa mudança surge na referência que o editorial faz ao "clima de diálogo e colaboração que impera hoje no Ministério de Educação", que assinou contrato com a Fundação Victor Civita possibilitando assim que cada uma das 220 mil escolas públicas de $1^{\circ} \mathrm{Grau}$ do país receba um exemplar de Nova Escola (Civita, 1986, p. 5). ${ }^{7}$

Alude-se também a "algumas empresas privadas" e a seu "espírito público", em decorrência do apoio dado ao novo empreendimento do Grupo Abril (idid., p. 5). Como diferença importante em face do editorial anterior, explicita-se este objetivo em relação à professora: a intenção de "valorizá-la; resgatar seu prestígio e liderança junto à comunidade" (idid., p. 5). Note-se que essa intenção parece deixar implícita a ideia de que houve um processo de desprestígio da profissão docente, um desprestígio que sequer está implícito no editorial da revista da década anterior. E o que se propõe como veículo que pretende contribuir para essa valorização recusa explicitamente o viés pedagógico.

Da análise comparativa entre os dois editoriais inaugurais, nota-se ainda uma diferença importante na forma como a revista é apresentada ao leitor. Na primeira publicação, além de ser mencionada a Editora Abril e de incluir a revista ESCOLA no registro dos empreendimentos dessa editora comercial, um forte tom de justificação das opções feitas perpassa o editorial como um todo. As justificativas começam no primeiro parágrafo, quando Civita procura explicar, como quem está brincando, o zero dado ao

\footnotetext{
${ }^{7}$ O convênio entre a Fundação Victor Civita e o Ministério de Educação garantiu durante cinco anos a distribuição gratuita de 300.000 exemplares para as escolas públicas de todo o país, cobrindo cerca de $70 \%$ do custo da revista. Boa parte da distribuição ocorria desse modo e o restante era vendido por assinatura ou em bancas de revista. A partir de 1991, o subsídio estatal acabou, mas no ano seguinte foi assinado um novo acordo, garantindo um exemplar de Nova Escola para cada escola urbana. (Vieira, 1995, p. 23; Costa e Silveira, 1998 apud Silveira, 2006, p. 9).
} 
professor na edição experimental, cujo número é zero e que na capa da revista poder-seia ler deste modo: ESCOLA zero para professores ou ESCOLA para professores zero.

Civita dirige-se deste modo ao professor: "Você deve ter estranhado ao receber um zero, quando seu esforço [...] merece a nota máxima" (Civita, 1971, p. 3). Com essa aparente brincadeira, lembrada já na primeira linha do texto, a intenção do editor parece ser a de criar um clima de informalidade e intimidade com o professor-leitor. ${ }^{8}$ Logo depois, Civita justifica a opção pela distribuição da revista em bancas de jornal, a escolha do $1^{\circ}$ Grau como foco da revista, a adesão entusiasta à reforma de ensino do regime militar e, por último, a opção pela forma jornalística numa revista pedagógica.

No segundo editorial, de meados da década de 1980, esse tom desaparece. Talvez porque não é mais necessário se justificar diante do professor-leitor pelas opções feitas. A ditadura militar acabou, vive-se em um regime democrático e a indústria cultural, já bem consolidada, continua a se fortalecer, expandindo-se nessa década em âmbitos antes inacessíveis, como é o caso dos periódicos dirigidos ao professor. Nos anos de 1980, o leitor-professor que a Editora Abril almejava, afeito aos modelos de leitura das revistas de bancas de jornal, parece estar pronto, após algumas décadas de publicações desse tipo e a conseqüente criação de novos hábitos de leitura.

Nesse período não se faz necessário justificar o tipo de periódico ofertado ao professor, com um padrão gráfico e editorial que contrastava com boa parte da tradição dos periódicos dirigidos ao professor ${ }^{9}$, sendo semelhante ao de outras revistas do Grupo Abril, destinadas a leitores comuns. Destes estava próximo o leitor-professor da revista Nova Escola: um professor que havia perdido parte considerável de seu estofo simbólico, da sua autoridade como mestre e intelectual, ao menos no modo como era visto pela revista nesse momento, como uma professora que perdeu seu antigo prestígio. Com esse leitor virtual, próximo de um leitor comum, a nova revista do Grupo Abril, agora apresentada como uma publicação de uma "entidade sem fins lucrativos" (Fundação Victor Civita), terá uma ampla repercussão entre os professores (Civita, 1986, p. 5). Finalmente, Civita e sua editora encontram o professor-leitor capaz de realizar o seu velho sonho.

Para concretizá-lo também foi essencial a contribuição do Ministério da Educação e Cultura (MEC), num duplo sentido. De um lado, graças ao contrato já mencionado com a Fundação Victor Civita, garantindo a sua distribuição nas escolas públicas de $1^{\circ} \mathrm{Grau}$ de todo o país. De outro, em razão do que deve ser avaliado reparando nas publicações do próprio MEC nos momentos em que a Editora Abril lança as suas revistas dirigidas ao professor.

Quando ESCOLA chega à sua terceira edição, com o n. 2, em abril de 1972, sem o patrocínio do MEC, o Ministério iniciava a publicação da revista Educação, cuja forma material também a tornava semelhante às revistas de banca de jornal, no tamanho, no emprego de fotos e outras características. Esse novo periódico inaugura um novo padrão

\footnotetext{
${ }^{8}$ Esse é apenas um dos vários recursos que a revista cria e emprega para se aproximar do leitor e buscar a sua identificação com a revista Em relação a outros recursos utilizados para produzir o mesmo efeito, vejase Revah e Toledo (2011).

${ }^{9}$ Uma das dimensões envolvidas nesse contraste é a aridez do tratamento de determinados temas presente na tradição de periódicos destinados ao professor primário e secundário e praticamente inexistente naquelas revistas educacionais do Grupo Abril (Revah e Toledo, 2010).
} 
quando comparado à publicação do ministério que o precede, a revista $M E C$, editada entre 1956 e 1970. Esta última é semelhante em sua forma material à maioria dos periódicos educacionais da época, com poucas imagens e um formato que pouco a diferenciava de boa parte dos livros. A revista Educação, que também surge tendo como mote a reforma de ensino da ditadura, destina-se a um público amplo, não limitado a determinado nível de ensino.

Poder-se-ia pensar que disputa certo espaço com a revista que a Editora Abril lança no mesmo período, ao menos quanto à sua forma material, que é um diferencial importante de ambas publicações em face do que então predominava entre os periódicos dirigidos ao professor. A última edição da revista Educação ocorre em jan./dez. de 1984 e, depois de pouco mais de um ano, surge Nova Escola, já sem o antigo concorrente e auxiliada inclusive pelo próprio MEC, que desse modo promove uma revista destinada ao professor que afirma não se inscrever no campo da Pedagogia, muito embora afirme que pretende valorizá-lo e ajudá-lo a melhorar no seu desempenho. Apoiada pelo MEC e com esse norte, como que renegando a dimensão que é própria da profissão de seu leitor, a nova publicação do Grupo Abril inicia o caminho de seu sucesso. ${ }^{10}$

O desejo que Civita explicita no sentido de não ser uma "publicação pedagógica" também cabe pensá-lo no registro da polêmica que surgiu no campo da educação escolar no início da década de 1980 (Civita, 1986, p. 5).

Havia então um embate gerado a partir de posições expressas por Dermeval Saviani (1984) quando apresenta a "teoria da curvatura da vara" e suas teses sobre a educação escolar brasileira, nas quais criticava o que situava em linha de continuidade com o movimento da Escola Nova das primeiras décadas do século passado. Segundo Saviani, dada a extrema valorização da pedagogia nova, apresentada como "portadora de todas as virtudes e de nenhum vício", era necessário curvar a vara para outro lado, para o lado da Escola Tradicional, considerada pela "concepção corrente" como portadora de "todos os vícios e nenhuma virtude" (idid., p. 62).

Saviani propunha então a superação dessas posições extremas e sugeria a busca de um ponto de equilíbrio. Um dos alvos desses questionamentos eram as posições, perspectivas e formas de educação alternativa que vinham se multiplicando desde meados da década de 1970 (Revah, 2005), envolvendo desde a Educação Popular até experiências educacionais desenvolvidas entre as camadas médias. ${ }^{11}$

Saviani e outros intelectuais, como Libâneo (1982) e Mello (1981), promoveram um intenso debate que procurava marcar posição em defesa de uma suposta Pedagogia tradicional, em oposição ao que eles situavam no âmbito da Escola Nova, destacando sobretudo o papel dos conteúdos do ensino. Além disso, defendiam suas posições esgrimindo o significante pedagógico, cujo valor pode ser pensado em face do significante educacional, largamente utilizado no âmbito das formas educacionais alternativas, entre as quais era comum o uso dos termos educador ou monitor no lugar de professor, sendo

\footnotetext{
${ }^{10}$ Segundo Silveira (2006, p. 11), em meados da década passada, a revista Nova Escola tinha "a segunda maior tiragem de revistas do país, perdendo apenas para outra publicação do Grupo Abril, a revista Veja”, totalizando cerca de meio milhão de exemplares.

${ }^{11}$ Um exemplo são as chamadas escolas alternativas da cidade de São Paulo (Revah, 1994). Em relação à educação popular, Saviani (1984, p. 71) refere-se a ela chamando-a de "escola nova popular" e diz que teria se constituído e implantado entre 1959 e 1964, na vertente oriunda das concepções de Paulo Freire.
} 
frequente também a recusa de certa formalidade característica das práticas escolares que o significante pedagógico poderia também trazer à tona.

Além disso, o uso do significante "pedagógico" inscreve-se na intenção de Saviani de recuperar "a especificidade do fenômeno educativo", que teria sido dissolvido em razão da identificação entre educação e política ou entre prática pedagógica e prática política, como teria ocorrido no âmbito da Educação Popular, conforme sugeria em seus textos (Saviani, 1984, p. 85-96). Surge assim, no encalço dos textos de Saviani, a perspectiva que muitos reconheciam por meio do nome pedagogia dos conteúdos, muito embora na academia fosse chamada de pedagogia crítico-social dos conteúdos, uma síntese superadora, na avaliação de seus mentores, que nascia situada no ponto de equilíbrio da polarização que há décadas vinha sendo (re)desenhada pelos discursos pedagógicos. ${ }^{12}$

No momento em que surge a revista Nova Escola, as questões próprias desse debate ainda estavam sendo processadas. A revista do Grupo Abril situa-se num terreno ideológico e discursivo que estava mais próximo do que era criticado por Saviani do que o contrário. Não só pelo teor de parte significativa das matérias dos primeiros anos, mas também tendo em vista dois aspectos. ${ }^{13} \mathrm{O}$ primeiro é a recusa da dimensão pedagógica no editorial inaugural, numa publicação que buscava valorizar o professor e ajudá-lo em seu trabalho.

Essa recusa vincula-se, provavelmente, a uma avaliação negativa da linguagem acadêmica presente em muitos periódicos educacionais, entendendo-se então que o professor de $1^{\circ} \mathrm{Grau}$ preferia um periódico que não fosse árido no tratamento dos temas que Ihe interessavam, um periódico que fosse atraente e que também evitasse o pedagogês, como parece pretender a revista Nova Escola quando enfatiza o seu caráter jornalístico. ${ }^{14} \mathrm{O}$ segundo aspecto corresponde ao que se encontra implicado no nome da revista e que se revela por uma simples inversão de seus significantes, de modo que Nova Escola transforma-se em Escola Nova. O passado ao qual fica implicitamente amarrada essa publicação remete, antes de mais nada, para esse pólo dos embates do início da década de 1980 e que vem à tona com o significante Escola Nova. ${ }^{15}$

Esse vínculo e o lugar em que a revista se situa diante da polêmica surgida nesses anos também transparece, no número inaugural, numa matéria escrita por Lia Rosenberg, a mesma pesquisadora que em fins da década anterior conduziu a equipe que fez um estudo de caso sobre a revista ESCOLA, na Fundação Carlos Chagas (Rosenberg et al,

12 Um primeiro marco dessa polarização pode ser situado no Brasil das décadas de 1920 e 1930, como evidenciam as pesquisas de Carvalho (2003).

${ }^{13}$ A respeito das matérias da Nova Escola dos primeiros anos e a presença do discurso da educação popular, veja-se Revah (2004, cap. 3).

${ }^{14}$ A esse propósito, Silveira lembra o que Frade sugere: "o fato de jornalistas estarem escrevendo para professores pode ser uma das maneiras encontradas pela mídia impressa de tentar evitar o 'pedagogês'" (Frade, 1999 apud Silveira, 2006, p. 14).

${ }^{15}$ A respeito do nome da revista, Vieira sugere dois sentidos relacionados com o significante Nova. É Nova Escola "porque veicula as mais recentes e atualizadas informações sobre a educação" e também "porque a leitura das informações veiculadas pela revista possibilitariam ao leitor-professor a inovação da escola" (Vieira, 1995, p. 13). 
1979). ${ }^{16}$ A esse respeito, o título da matéria é bem sugestivo: "Voltar ao passado não resolve o nosso futuro" (Rosenberg, 1986, p. 24).

O título é complementado por este subtítulo: "Melhor do que sonhar com um retorno aos tempos antigos é abrir bem os olhos para a realidade presente, buscando os meios de modificá-la" (p. 24). No corpo do texto, Rosenberg crítica educadores que não nomeia, mas que um professor-leitor atento e permeável aos debates da época poderia remeter à polêmica promovida pelos intelectuais que vinham defendendo a chamada pedagogia tradicional e desenvolvendo a pedagogia dos conteúdos. Essa referência é sugerida por estas linhas da matéria: "O interessante é que mesmo educadores comprometidos com a idéia de uma escola democrática pregam a volta da escola antiga, sem pensar que essa volta é um recurso extremamente elitista, na medida em que, antigamente, só a elite tinha acesso aos estudos" (Rosenberg, 1986, p. 25).

Nessa matéria, mas também em outras e ainda em razão do que o nome da própria revista sugere, nota-se que a linha editorial escolhida procura manter uma maior proximidade com o pólo recusado pelos intelectuais que articulavam a pedagogia dos conteúdos. Não por acaso, nessa revista emergirá com intensidade inusitada o que muitos pesquisadores colocam em linha de continuidade com a Escola Nova: o construtivismo, que chega às páginas da revista com a figura da psicóloga e pesquisadora Emilia Ferreiro, quase que transformada em um messias. ${ }^{17}$ Messias com inúmeros seguidores, na construção imaginária que a revista faz e que tem a sua contrapartida efetiva na febre construtivista de fins da década de 1980, quando o sonho de Civita já é uma realidade. $^{18}$

\section{Lendo nas entrelinhas: as opções editoriais nas capas inaugurais}

Definidas em conjunturas políticas bem diversas (ditadura versus democracia) e fazendo parte, ao que tudo indica, do mesmo sonho, as opções editoriais de ESCOLA e Nova Escola revelam-se também naquilo que as capas inaugurais instituem. A primeira, de outubro de 1971, surge com esta manchete: Educação física com gosto de recreio, acompanhada de uma foto que ocupa a maior parte do espaço da capa e que sugere um professor de educação física com alunos em torno dele, vestidos em sua maior parte com roupas brancas e jogando pequenas bolas para o alto, num gramado e ao ar livre (figura $1)$.

Pode-se dizer que a imagem sugere o gosto de recreio que a manchete destaca. Aqui é importante notar que o tema escolhido para a edição inaugural diz respeito a uma área do ensino fortemente associada, na educação escolar brasileira, aos

\footnotetext{
${ }^{16} \mathrm{Na}$ avaliação feita à época pela equipe da Fundação Carlos Chagas, a revista ESCOLA foi considerada "significativa dentro do panorama da literatura pedagógica no Brasil" e, dentre os periódicos educacionais analisados, "a única publicação cujas características aproximavam-se do modelo visado" (Rosenberg et al, 1979, p. 58-9). Esse modelo tomou como base critérios estabelecidos por Jorge Nagle.

${ }^{17}$ Em relação à construção da imagem de Ferreiro como um messias, veja-se a análise de Vieira (1995, p. 57).

18 "Febre construtivista" é uma expressão usada por Vasconcelos (1996, p. 1). Em sua pesquisa sobre a presença da obra de Piaget no Brasil, alude também à continuidade entre o movimento da Escola Nova e o construtivismo.
} 
militares. ${ }^{19}$ Entretanto, o caráter militar que, com frequência, a educação física adquiriu em sua versão escolar, não é o que transparece na imagem de capa, nem o que a manchete sugere. Muito pelo contrário, fala-se em recreio, uma palavra cujo significado remete-nos ao que na alternância dos tempos escolares deve ser situado em oposição às aulas e, portanto, ao que poderíamos pensar como sendo da ordem do esforço, da disciplina, de tarefas definidas pelo professor e que devem ser cumpridas, por mais enfadonhas que sejam. Ao menos isso é o que sugere a matéria que corresponde ao destaque de capa, embora fazendo o alerta de que se trata mesmo de uma aula. A matéria é aberta com este texto: "É divertido. As crianças adoram. Parece o recreio. Mas não é. Estamos na aula de EDUCAÇÃO FÍSICA". ${ }^{20}$

Na matéria, com várias cenas de alunos de $2^{a}$ série muito envolvidos nas atividades que estão realizando, em algumas com a presença do professor, em fotos sempre acompanhadas por um texto explicativo que na verdade é a própria matéria, fala-se das "revolucionárias aulas" do "jovem professor" Salvador Felisetti, do Externato Jaraguá, em São Paulo. Nessa escola, afirma-se na introdução da matéria, "pode estar morrendo" a "clássica sessão de Educação Física, com ordenados exercícios de flexões dos membros e dos músculos dorsais" (ESCOLA n. 0, out./1971, p. 44). O professor "encontrou conceitos novos, uma espécie de poesia objetiva que destrói a clássica imagem do bigodudo cavalheiro em calções, fazendo sua ginástica matinal" (idid., p. 44). Ele "detesta as ordens de comando berradas às equipes em posição fundamental" (idid., p. 44).

Nos textos que acompanham as fotos descreve-se o que as crianças estão fazendo e mencionam-se orientações ou princípios que devem ser seguidos, por vezes reproduzindo falas do professor: "A criança deve ser estimulada a se autoconhecer, a pôr para fora todo o seu potencial de criatividade", "O que vale é a imaginação", "O bom humor estimula a criatividade da criança", "ele [o professor] incentiva os alunos a criar seus próprios movimentos", "É preciso não ter medo de receber da criança, é preciso estar no meio delas. Elas devem sentir o professor" (idid., p. 45-6). Nas atividades descritas ressalta-se a dimensão lúdica, o fato das crianças brincarem, de estarem alegres, de tomarem a iniciativa e, sem que o saibam, de estarem "desenvolvendo um salutar espírito de equipe" (idid., p. 46). E dessa maneira a "aula chega ao fim, as crianças parecem descontraídas e felizes" (idid., p. 46).

A aula com gosto de recreio também pode ser pensada no registro que o mesmo significante recreio institui na propaganda que a Editora Abril faz, nesse mesmo número da revista ESCOLA, da sua revista Recreio. Nela, logo abaixo do nome, foi escrito este slogan: "diverte ensinando e ensina divertindo" (ESCOLA n. 0, out./1971, p. 24). Um slogan que bem caberia para o sentido que se procura dar à aula de educação física descrita na matéria antes analisada.

Outro aspecto que vale a pena destacar é o conteúdo da página que segue à página em que termina essa matéria e que o professor-leitor pode olhar logo que termina, sem ter

\footnotetext{
${ }^{19}$ Em relação ao caráter militar da educação física, Horta lembra-nos que a partir de 1937 ela "passará a ser um setor privilegiado de atuação dos militares, que pretenderão utilizá-la para a concretização da sua presença nas escolas" (1994, p. 2). Uma presença apontada também por Schneider, que em referência a essa área na primeira metade do século 20 refere-se aos militares como "os principais atores da Educação Física no Brasil" (2010, p. 213).

20 "Educação física" é escrito em caixa alta e com um tamanho maior que o texto que precede essa expressão, sugerindo assim que ela seria o título da matéria. Cf. ESCOLA, n. 0, out., 1971, p. 44.
} 
que virar a página. Trata-se de uma propaganda, de página inteira, de um "Guia para aulas de Educação Física" produzido pela empresa Alpargatas (idid., p. 47). Na parte superior dessa página, em caixa alta e ocupando quase que um quarto do espaço, foi colocada esta frase: "AO MESTRE, COM CARINHO". No esclarecimento sobre as características do guia, afirma-se que esse produto da "São Paulo Alpargatas" colabora com a iniciativa do governo federal, que estendeu a obrigatoriedade da educação física a todos os níveis escolares. Lembra-se também que a publicação foi tão bem recebida que traz mensagem especial do ministro Jarbas Passarinho.

Como se vê, a revista ESCOLA opera um deslocamento em relação às representações que podemos supor eram comuns no que se refere à educação física e faz isso numa área e com um significante que lembram, sem muito rodeio, o vínculo com os militares, numa conjuntura na qual essa ligação remete para o regime militar, na sua fase mais repressiva, nos chamados anos de chumbo. A ligação assim produzida, junto com os deslocamentos que a Editora Abril procura provocar, fazem pensar em exercícios próprios de um contorcionista, com o resultado esperado: um corpo estranho.

Talvez tenha sido essa a impressão de parte dos professores-leitores em face da nova revista da Editora Abril, que não parece ter conseguido o universo de leitores pretendido. Ao estampar na capa da edição inaugural a manchete Educação Física com gosto de recreio, nessa conjuntura política e expressando a sua entusiástica adesão às políticas educacionais do regime militar, a Editora Abril abriu um leque de significações possíveis de serem construídas por seus leitores que hoje nos escapam. Entretanto, não parece arbitrário pensar que o que a editora faz e diz a seus leitores, sobretudo aos que se posicionavam criticamente em face do regime militar, concernia a sentidos que muito extrapolavam o que aquele título a princípio sugere. São sentidos que devem ser procurados nas entrelinhas.

A posição inaugural da revista ESCOLA bem poderia ser resumida realizando a substituição significante sugerida pelo vínculo entre a educação física e os militares, de modo a transformar aquela manchete obedecendo às conexões e os deslocamentos próprios da série significante implicada nesse caso e que assim poderia ser escrita: educação física - militares - ditadura. Disso resultaria uma frase capaz de provocar certo estranhamento: Ditadura com gosto de recreio, mas cujo sentido não parece disparatado para situar o que a revista ESCOLA tende a instituir, pelo menos no início, como representação do regime militar para seus leitores, em contraste com o que o regime representava para muitos brasileiros, no período de maior repressão política e cultural. $\mathrm{E}$ também em contraste com os valores que transparecem em matérias sobre atividades escolares, como a da reportagem de capa da edição inaugural. O estranhamento diz respeito à conjunção que a revista ESCOLA produz nesse período ao tentar deslocar o sentido normalmente associado à área de Educação Física, com a sua forte conotação militar, no momento em que a presença militar é mais asfixiante.

Muitas coisas estão em jogo no uso do significante Educação Física na edição inaugural. E o que a revista ESCOLA faz por meio desse significante, com a rede simbólica que nele conflui e que a revista (re)ordena, opera no sentido de alterar as representações da área, mas também indiretamente do regime militar, como se tudo tivesse gosto de recreio. Afinal, o que a revista parece dizer a seu professor-leitor é que, até mesmo numa área tradicionalmente sensível aos donos do poder, a mudança é bem 
vinda e na direção dos valores apregoados em sua reportagem de capa, envolvendo alegria, bom-humor, descontração, criatividade, imaginação e um salutar espírito de equipe. A capa inaugural parece querer transmitir esses valores a seu professor-leitor, mas a conjunção produzida talvez tenha operado, em muitos casos, no sentido de anular seu efeito como dispositivo de captura do leitor, operando até no sentido contrário.

A revista Nova Escola surge na década seguinte com um projeto gráfico que lembra o periódico anterior, a começar pelo tamanho da revista e a capa (figura 2). Nas duas publicações, nos cabeçalhos das capas, sobressaem os nomes sobre um fundo branco. Em ESCOLA, o nome está escrito em caixa alta e cor vermelha; em Nova Escola, com um cabeçalho proporcionalmente maior quando considerado o tamanho da revista, o nome está em caixa alta e cor amarela no caso da palavra Nova e caixa alta (letra inicial) e baixa para Escola, escrita na cor verde. Mas o que sobressai nesta última é a palavra Escola, devido às cores utilizadas e, sobretudo, ao tamanho (a palavra Nova foi colocada verticalmente sobre a letra inicial de Escola). Nos cabeçalhos há também outras informações, em caracteres bem pequenos, como o número do exemplar e as expressões que complementam o título (para professores ou para professores do $1^{\circ} \mathrm{Grau}$ ), além de outras informações no caso de Nova Escola, como data e preço, que na primeira publicação figuram na parte inferior esquerda da capa, em caracteres bem pequenos e sobrepostos a uma foto.

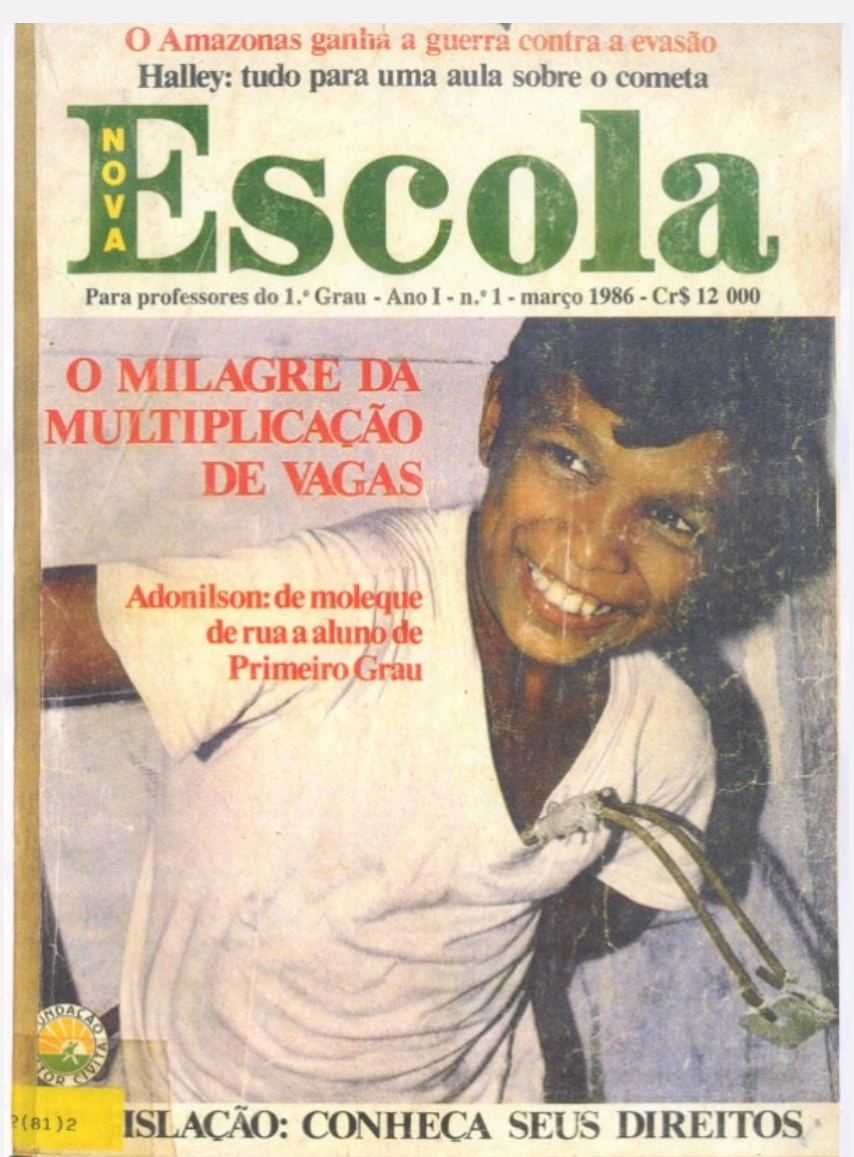

Constam ainda chamadas para outras matérias nos dois cabeçalhos, em letras bem menores se comparadas com os nomes das revistas: em ESCOLA, há três chamadas em um retângulo preto colocado do lado direito; em Nova Escola há duas precedendo o próprio nome. A capa inaugural das duas revistas apresenta uma foto que abarca quase toda a mancha que resta, com bordas laterais que prolongam o fundo branco do cabeçalho, sendo a borda do lado direito mais larga no caso de ESCOLA.

O fundo branco prolonga-se ainda na parte inferior, sob a forma de uma estreita faixa horizontal com uma chamada para uma matéria, em ambos os casos envolvendo a legislação. Em ESCOLA, o leitor é informado que a nova lei do ensino (5.692/71) é explicada nessa edição; enquanto em Nova Escola o leitor é chamado para que conheça seus direitos. Nas duas publicações, como já foi mencionado, foram estampados sobre as fotos os logotipos da Editora Abril ou da Fundação Victor Civita, na parte inferior esquerda. Como se vê, as capas inaugurais são graficamente bastante semelhantes e dão lugar a pensar que a segunda publicação retoma simplesmente a segunda. 
A revista Nova Escola nasce em outra conjuntura política e o registro que ela institui e no qual se inscreve também pode ser analisado observando com atenção a capa inaugural, de março de 1986. A capa apresenta a foto do sorridente menino Adonilson, com um estilingue pendurado na camiseta, e esta manchete sobreposta à imagem: "O milagre da multiplicação de vagas", complementada com este subtítulo em letras menores: "Adonilson: de moleque de rua a aluno de Primeiro Grau" (Nova Escola n. 1, mar., 1986, p. 46). O título da reportagem de capa repete parte da manchete ("O milagre da multiplicação"), com o subtítulo "Escolas improvisadas criam novas vagas" (idid., p. 46). A reportagem é aberta com uma foto do tamanho de um terço de página mostrando uma das doze barracas de lona que a Secretaria de Educação de Manaus instalou em praças da cidade (idid., p. 46). A matéria informa que 600 crianças com idades de 7 a 14 anos nelas se abrigam, tendo abandonado a vida de pedinte.

Ainda na primeira página, repete-se a imagem de capa e há mais duas fotos, uma delas com três meninas ali abrigadas. O texto introdutório diz que há cinco milhões de crianças que "não obtêm vagas nas escolas espalhadas pelo Brasil" e pergunta: "como ampliar o número de vagas, quando nem sempre há recursos para construir novas escolas?" (idid., p. 47). A matéria apresenta a resposta dada "com arrojo e inventividade" pelos "responsáveis pela Educação, em algumas regiões brasileiras" (idid., p. 47). No corpo da reportagem, o texto é iniciado apresentando Adonilson com estas palavras: "Adonilson Moraes da Rocha, 10 anos, pequena estatura, corpo franzino. Durante muito tempo cheirava cola e fumava como adulto, enquanto vadiava pelas ruas. Seu pai vendia sacos, sua mãe trabalhava como doméstica. Assim era a vida que Adonilson ia levando" (idid., p. 47). Outros aspectos da vida que levava na rua são ainda mencionados, além da mudança que teve quando começou a frequentar as barracas do "Projeto Meu Filho", da prefeitura de Manaus (idid., p. 47). São também reproduzidas algumas críticas feitas a esse projeto e apresentadas outras iniciativas, desenvolvidas em Recife (escolas dentro de ônibus) e em Brasília (escolas que funcionavam em barracas).

Da capa inaugural e da reportagem correspondente, vale a pena ressaltar alguns elementos para situar o lugar em que a revista se instala quando surge. A foto inicial, apresentando um menino por meio do significante moleque de rua e com um estilingue, está como que a sugerir que a sua realidade, a realidade da rua, também entra na escola: uma escola que recebe Adonilson, o transforma em aluno e que ela própria parece aberta à transformação sugerida pelo seu sorriso e pelo insólito apetrecho.

O apelo ao leitor para que considere a realidade de seus alunos e a importância da escola no sentido de se manter permeável a essa realidade é uma das dimensões implicadas nessa foto e que a matéria evidencia. Note-se também que a realidade escolhida é a de quem vive na marginalidade. Adonilson dormia na rua, na porta de uma igreja, tinha sido preso várias vezes e "castigado com palmatória por policiais" (Nova Escola n. 1, mar., 1986, p. 47). A resposta encontrada pela prefeitura de Manaus situa-se também à margem das instituições socialmente legitimadas. No período em que sai essa reportagem, todos esses aspectos encontravam-se fortemente associados às formas de educação que podiam ser qualificadas de alternativas, de acordo com o que esse significante demarcava em discursos que também diziam respeito à chamada educação popular. 
Outro aspecto não desvinculado do registro da educação alternativa, é a identificação do moleque de rua. Não se trata de um aluno anônimo; dele são destacados aspectos que permitem identificá-lo e que o singularizam. A matéria, inclusive, começa desse modo, apresentando Adonilson. O apelo que parece dirigido ao professor-leitor é que olhe para o aluno levando em consideração duas dimensões: as suas particularidades e a realidade mais ampla que o ultrapassa, mas que vem junto com ele. O que Lia Rosenberg pede ao leitor na matéria já referida, dessa mesma edição, aponta no mesmo sentido: "Em vez de lamentar que essa criança não seja a ideal, precisamos nos debruçar sobre esse aluno concreto, real, de verdade" (Rosenberg, 1986, p. 25).

$\mathrm{Na}$ reportagem de capa, o apelo feito ao professor é no sentido de sensibilizá-lo, sobretudo em relação às crianças que vivem nas piores condições, à margem da sociedade. A escola, o professor, as autoridades devem tomar como ponto de partida essa criança-aluno, com a sua realidade. Dessa realidade deve partir a ação da escola e do professor. No caso dessa matéria, em boa medida o que está em causa é a realidade das crianças sem escola, mas também envolve as que nela se encontram, como se depreende de outras reportagens dos primeiros anos da revista. Essa é a nova escola que a revista da Editora Abril propõe e onde ela inicialmente se instala, delimitando simultaneamente o lugar do aluno, do professor, da escola e dela própria. O ponto de partida é a criança-aluno e a sua realidade. É desse modo que determinados vínculos são estabelecidos, com o passado (Escola Nova) e com o presente (educação popular, educação alternativa).

Sobre a política editorial da revista Nova Escola, nesse primeiro período, que deve ser estendido até a emergência do construtivismo em fins da década de 1980, nota-se que a publicação manteve-se atenta aos debates no campo da educação escolar e à força do que Saviani e outros intelectuais criticavam. Esse debate provocou alguns deslocamentos, como é possível notar no campo da educação alternativa (Revah, 1994), mas não chegou a entronar a pedagogia dos conteúdos, que foi sobrepujada pelo construtivismo e pelo que neste havia de outros discursos educacionais e momentos do passado, como é o caso do que pode ser visto como prolongamento de princípios e ideias presentes no movimento da Escola Nova.

As opções editoriais das duas revistas educacionais do Grupo Abril, nascidas em conjunturas políticas e educacionais bem diferentes, mostram que ambas buscavam manter uma permanente sintonia com os problemas de seu tempo, como era de se esperar, sobretudo em periódicos de uma editora comercial. À primeira vista, não há diferenças significativas quando considerada a forma material e a opção pela linguagem jornalística, que se mantêm como uma característica, hoje bem sucedida. $\mathrm{O}$ mesmo poderia ser dito em relação à valorização de certos princípios que perpassam diversas matérias sobre a atuação do professor em sala de aula e que em ambos os casos poderiam ser vinculados à tradição que remonta à Escola Nova. Entretanto, o modo como cada publicação se posiciona muda sobremaneira se atentarmos para as diferentes conjunturas políticas nos momentos em que são lançadas.

O modo como a revista ESCOLA procura situar-se em face de seu suposto leitor em grande parte é definido pelo valor atribuído à reforma do ensino que cria o $1^{\circ}$ e $2^{\circ}$ Graus, que é provavelmente o tema de maior repercussão entre os professores quando de seu lançamento. Dirigida ao professor de $1^{\circ} \mathrm{Grau}$, leitor que ainda não existe propriamente, a 
revista engaja-se nessa criação e opera com significantes que a ditadura mobiliza e nos quais ela própria se enreda, a começar pela capa inaugural.

O seu fracasso comercial pode ser avaliado em vista disso, de um leitor visado que ainda não existe e que ela busca criar recortando a realidade escolar com significantes da reforma e do âmbito em que ela nasce. Em contrapartida, o que é possível constatar nesse momento é a existência de muitos professores que se vêem afetados pela reforma, que não participaram da sua elaboração e que são chamados a participar de forma entusiasta da sua execução.

Dessa maneira são também incitados a pôr em prática o que os desloca da sua posição, pois o que a reforma promove interfere nas representações historicamente construídas sobre o professor primário e o professor secundário, no caso do ginásio, relativas a tradições distintas e até opostas. Desde então, porém, eles ficam unidos na mesma categoria por meio das representações mobilizadas para definir esse novo lugar do professor de $1^{\circ}$ Grau. ${ }^{21} \mathrm{O}$ significado disso para os professores, no qual é preciso incluir medidas como o fim dos exames de admissão ao ginásio, é um elemento a considerar quando se pensa na repercussão da revista ESCOLA entre eles.

A revista Nova Escola dirige-se a um leitor que, de certo modo, já existe, em vários sentidos. Um deles concerne ao professor de $1^{\circ} \mathrm{Grau}$, após mais de uma década da lei $\mathrm{n}$. 5.692/71 que criou esse nível do ensino. O apelo ao professor-leitor agora é feito por meio da imagem de uma criança que estava fora da escola, que representa o que ficou à margem dela e que diz respeito ao universo das experiências alternativas que o próprio Estado promove para conter a realidade que a escola não incorporou.

A revista situa-se assim, na capa inaugural, com a imagem do menino Adonilson, que fez o trânsito de moleque de rua a aluno de Primeiro Grau, num circuito que abarca a dupla face dentro/fora, interior/exterior da escola, envolvendo tanto o que pode ser situado no âmbito das ações do Estado no que se refere à educação escolar, à educação formal, quanto o que pode ser visto como relativo ao circuito das experiências menos formalizadas e próximas da chamada educação popular. Esta, vale lembrar, dizia respeito a um circuito de experiências educacionais vedado durante a ditadura, pelo menos até o fim do período mais repressivo, em particular as experiências que explicitamente se inspirassem na obra de Paulo Freire. Essas e outras conexões iniciais, que implicitamente a revista Nova Escola estabelece com o passado e com o presente, situam-na de forma diferente em face de seus possíveis leitores, se comparada à publicação anterior. Pelo menos isso é o que emerge como intenção do editor: situar-se de outro modo tendo em vista a mudança de conjuntura política e de professores-leitores que já não são os mesmos de outrora.

Esses professores-leitores são os que agora fazem a sua própria reforma, mas desta vez reforma silenciosa, conforme anuncia desse modo a manchete de capa do segundo número da revista Nova Escola, de abril de 1986. O subtítulo da manchete desse número é: Como os professores estão mudando o $1^{\circ} \mathrm{Grau}$. Portanto, já não são as autoridades que fazem essa mudança, nem é uma reforma feita sem a participação deles e vinda de cima, da alta hierarquia governamental. É o que também sublinha o texto que abre a matéria correspondente ao destaque de capa: "Discretos e eficazes, eles adaptam os

${ }^{21}$ Sobre esse ponto, veja-se Revah e Toledo (2011). 
currículos à realidade de seus alunos. Corajosos e criativos, desafiam as leis para suprir a falta da pré-escola" (Nova Escola n. 2, abr./1986, p. 10).

A representação feita desses professores-leitores almejados agora pelo Grupo Abril, que desafiam as leis e que a revista em seu primeiro número incita a conhecer seus direitos, conforme consta numa das chamadas da capa inaugural, está bem distante da que foi produzida pela outrora revista ESCOLA em relação a seus professores-leitores. Estes últimos foram encorajados a participar de "uma das mais audaciosas fases de toda a história do ensino no Brasil" (Civita, 1971, p. 3), com uma reforma já definida e que a revista explica ao professor, conforme consta na chamada de capa já referida: $A$ nova lei do ensino explicada. Apesar desse contraste, é preciso ressalvar que a tal reforma silenciosa, com o norte dado pelos professores, muda de caráter conforme o leitor adentra na matéria correspondente.

Percebe-se, então, que quem está fazendo a reforma são as autoridades, pois o que é referido são iniciativas de diretores de escolas públicas e secretarias de educação estaduais e municipais. Quer dizer, o lugar do professor construído nessa segunda capa da revista Nova Escola se esvanece conforme lemos a matéria de capa, configurando-se assim um outro lugar para o professor.

Mas o que é importante salientar a esse respeito é como a nova publicação da Abril busca se posicionar em face da nova conjuntura política e do tipo de professor-leitor que antecipa, tudo isso revelando-se no que a revista destaca nas primeiras edições e na construção que ela faz, por exemplo, nessa segunda capa da revista. Esse leitor virtual não é mais o executor da reforma de ensino do regime militar, agora é o que toma em suas mãos o destino da educação do país e que valoriza o que havia ficado à margem da escola e das formas autorizadas pelo regime anterior.

Apesar das diferenças relativas a conjunturas políticas distintas (ditadura versus democracia), nelas próprias é possível encontrar o que as une e que vincula as duas publicações, definindo igualmente o norte dos empreendimentos empresariais do Grupo Abril, assim como é próprio de outros em que a obtenção de lucros é a prioridade. Isso precisamente é o que destaca um dos diretores de redação da revista ESCOLA, quando indagado sobre os objetivos ao ser lançada:

Para o diretor de redação durante os 20 primeiros números, a editora visava a contribuir para o desenvolvimento da Educação no Brasil. A pessoa que o sucedeu no cargo, entretanto, tem outra visão do problema. Para ele, a editora visava a obtenção de lucros, com essa como com as outras revistas editadas. Já o responsável pela comercialização, considera que o objetivo era contribuir para a Educação, sem perder muito dinheiro. (Rosenberg et al., 1979, p. 60)

A concretização do velho sonho de Victor Civita e que pode ser estendido ao Grupo Abril, com as suas várias faces e traduções possíveis (vender, vender, vender, distribuir cultura, ser uma editora de massas), implicou na realização de um percurso semelhante ao de outros empreendimentos empresariais brasileiros que fizeram alianças que hoje convêm não lembrar. Como aponta Renato Ortiz (1991), nas décadas de 1960 e 1970 o Estado atuou simultaneamente como repressor e incentivador das atividades culturais, 
disciplinando-as desse modo. A censura apresentava nesse período dupla face: reprimia e disciplinava.

Os grupos privados que não se atrelavam às políticas e posições da ditadura colocavam em risco o sucesso de seus empreendimentos, como aconteceu com o jornal Última Hora e a TV Excelsior. Associados aos militares, empreendimentos empresariais como os da TV Globo contaram com "a liberdade necessária para realizar seus projetos culturais" (Ortiz, 1991, p. 155). A Editora Abril não parece ter se distinguido deles. Para ser bem sucedida, para efetivar o que seu fundador almejava, buscou uma aproximação com os militares, o que ainda cabe ser investigado com maior profundidade. De qualquer modo, cabe lembrar o que Pereira (2005) aponta: "a expansão da Editora Abril ocorre exatamente nos primeiros dez anos do regime militar. Ela foi uma das empresas de comunicações mais beneficiadas pelas políticas econômicas dos militares" (p. 243).

Na revista ESCOLA, o Grupo Abril parece associar-se aos militares sem meias palavras. Quando o regime militar acaba e a redemocratização do país se efetiva, entra na nova trilha, mas não sem deixar de apagar determinadas marcas do próprio passado, como se observa no editorial inaugural da revista Nova Escola, no qual não se menciona a publicação anterior, e ainda no histórico que o Grupo Abril torna público sobre a sua própria trajetória. Nesta, a revista ESCOLA sequer parece ter existido, à semelhança de tudo o que poderia afetar a imagem do grupo e de seu fundador e que não é difícil de encontrar quando se investiga em que consistiu a relativa independência do Grupo Abril. ${ }^{22}$

\section{Referências}

CARVALHO, Marta Maria Chagas de. A escola e a República e outros ensaios. Bragança Paulista: Edusf, 2003.

CHARNIZON, Ana. A modelagem de leitores e de leituras no discurso midiático da revista Nova Escola. Belo Horizonte: UFMG, 2008. 180f. Dissertação (mestrado em Educação). Faculdade de Educação, Universidade Federal de Minas Gerais.

CHARTIER, Roger. A história cultural: entre práticas e representações. Lisboa/Rio de Janeiro: Difel/Bertrand, 1990.

CIVITA, Victor. Apresentação. In: ESCOLA. São Paulo: Abril, n. 0, out., 1971, p. 3.

CIVITA, Victor. Carta do editor. In: Nova Escola. São Paulo: Abril, n. 1, p. 5.

CIVITA, Victor et al. Caro Professor. In: ESCOLA. São Paulo: Abril, n. 26, 1974, p. 3.

ESCOLA. N. 0 a 27. São Paulo: Abril, 1971-1974.

HORTA, José S. B. O hino, o sermão e a ordem do dia: a educação no Brasil (19301945). Rio de Janeiro: UFRJ, 1994.

LIBÂNEO, José C. Tendências pedagógicas na prática escolar. Ande, São Paulo, n. 6, 1982, p. 11-19.

MELLO, Guiomar N. Ensino de $1^{\circ}$ grau: direção ou espontaneísmo? Cadernos de Pesquisa. São Paulo: FCC, n. 36, 1981, p. 87-91.

\footnotetext{
${ }^{22}$ A respeito da elisão da revista ESCOLA da história que o Grupo Abril produz e divulga sobre a sua própria trajetória, veja-se Revah e Toledo (2011).
} 
NOVA ESCOLA, ano 1, n. 1 e 2, março e abril de 1986.

ORTIZ, Renato. A moderna tradição brasileira. São Paulo: Brasiliense, 1991.

PEDROSO, Leda A. A Revista Nova Escola: política educacional na Nova República. Campinas: Unicamp, 1999. 289f. Tese (doutorado em Educação). Faculdade de Educação, Universidade Estadual de Campinas.

PEREIRA, Mateus H. F. Na nossa terra, em se plantando, elefante dá: Editora Abril (19502006) e livros vendidos em bancas de jornal. In: BRAGANÇA, Aníbal; ABREU, Márcia (org.). Impresso no Brasil: dois séculos de livros brasileiros. São Paulo: Unesp, 2010, p. 303-316.

PEREIRA, Mateus H. F. A trajetória da Abril Cultural (1968-1982). Em questão. Porto Alegre, v. 11, n. 2, 2005, p. 239-258.

REVAH, Daniel. A educação alternativa. In: RISÉRIO, Antonio et al. Anos 70: trajetórias. São Paulo: Itaú Cultural/lluminuras, 2005.

REVAH, Daniel. Construtivismo: uma palavra no circuito do desejo. São Paulo: USP, 2004. 532f. Tese (doutorado em Educação). Faculdade de Educação, Universidade de São Paulo.

REVAH, Daniel. Na trilha da palavra alternativa: a mudança cultural e as pré-escolas alternativas. São Paulo: USP, 1994. 303f. Dissertação (mestrado em Educação). Faculdade de Educação, Universidade de São Paulo.

REVAH, Daniel; TOLEDO, Maria Rita. A indústria cultural e a política educacional do regime militar: o caso da revista Escola. Revista Brasileira de História. São Paulo: Anpuh, v. 30 , n. 60,2010 , p. $77-95$.

REVAH, Daniel. O regime militar na (des)memória da editora Abril: a revista ESCOLA e a difusão da lei 5.692/71. História da Educação, Porto Alegre: Asphe, v. 15, n. 33, 2011, p. 137-161.

ROSENBERG, Lia et al. Publicações para professor: um estudo de caso. Cadernos de Pesquisa, São Paulo: FCC, n. 30, 1979, p. 57-64.

ROSENBERG, Lia. Voltar ao passado não resolve o nosso futuro. In: Nova Escola, n. 1, 1986, p. 24-25.

SAVIANI, Dermeval. Escola e democracia. São Paulo: Cortez, 1984.

SCHNEIDER, Omar. Educação physica: a arqueologia de um impresso. Vitória: Edufes, 2010.

SILVEIRA, Fernanda. R. Um estudo das capas da revista Nova Escola: 1986-2004. Campinas: Unicamp, 2006. 144f. Dissertação (mestrado em Educação). Faculdade de Educação, Universidade Estadual de Campinas.

VASCONCELOS, Mário Sérgio. A difusão das idéias de Piaget no Brasil. São Paulo: Casa do Psicólogo, 1996.

VIEIRA, Martha L. Construtivismo: a prática de uma metáfora - forma/conteúdo do construtivismo em Nova Escola. Belo Horizonte: UFMG, 1985. 75f. Dissertação (mestrado em Educação). Faculdade de Educação, Universidade Federal de Minas Gerais. 
DANIEL REVAH é professor adjunto do curso de Pedagogia da Unifesp, campus Guarulhos; doutor em Educação; pesquisador dos grupos de pesquisa História Cultural da Escola e dos Saberes Pedagógicos: impressos e modelos culturais e Laboratório de Estudos e Pesquisas Psicanalíticas e Educacionais sobre a Infância Lepsi-IP/FE-USP. Desenvolve pesquisas nos campos da filosofia da educação, história da educação e psicanálise, com foco nos discursos educacionais.

Endereço: Rua Professor Basileu Garcia, 95 - 05410-060 - São Paulo - SP - Brasil. E-mail: daniel.revah@unifesp.br.

Recebido em 13 de junho de 2012.

Aceito em 2 de outubro de 2012. 